Review Article

\title{
Soil Fauna as Webmasters, Engineers and Bioindicators in Ecosystems: Implications for Conservation Ecology and Sustainable Agriculture
}

\author{
Sefi Mekonen Ertiban \\ Department of Biology, Collage of Natural and Computational Science, Debre Berhan University, Debre Berhan, Ethiopia \\ Email address: \\ mekonen.sefi@gmail.com
}

To cite this article:

Sefi Mekonen Ertiban. Soil Fauna as Webmasters, Engineers and Bioindicators in Ecosystems: Implications for Conservation Ecology and Sustainable Agriculture. American Journal of Life Sciences. Vol. 7, No. 1, 2019, pp. 17-26. doi: 10.11648/j.ajls.20190701.14

Received: January 24, 2019; Accepted: March 14, 2019; Published: April 9, 2019

\begin{abstract}
Soil biodiversity comprised the organisms that spend all or a portion of their life cycles within the soil or on its immediate surface. Soil Fauna are those organisms that inhabit the soil (include arthropods, nematodes, molluscs, protozoa, rotifera, etc...). Of the total diversity of living organisms that has been described to date, $23 \%$ is soil animals. They are the dominant animal group in many terrestrial ecosystems and may have higher biomass on an area basis. According to their body size, soil fauna categorized into microfauna, mesofauna and macrofauna. In both natural and agricultural systems, soil organisms perform vital functions in the soil. Soil fauna are responsible for many ecosystem services like soil formation, nutrient cycling, soil restoration and food webs. These functions range from physical effects to chemical and biological processes. They burrowing and feeding activities result in improved aeration and water infiltration, incorporation of organic matter into the soil, and stabilization of soil aggregates, leading to their designation as ecosystem engineers. They are also play a role in significant indicators of soil health. Human activities leads to loss of soil structure and function through reduction of soil fauna diversity, habitat fragmentation, nutrient cycling and organic matter destruction. A combination of those factors can lead to ecosystem destruction. Soil fauna communities are highly sensitive to environmental variation and destabilization. Moreover, soil fauna are a useful bio-indicators for human disturbance on ecosystem.
\end{abstract}

Keywords: Bio-indicator, Ecosystem Engineers, Ecosystem Services, Soil Fauna

\section{Introduction}

Organisms that spend all or a portion of their life cycles within the soil or on its immediate surface is soil biodiversity [1]. Although the vast majority of species are undescribed, soil is harbor and reservoir of terrestrial biodiversity [2-3]. Soil organisms are important for soil health and fertility in both natural ecosystems and agricultural systems [1]. Among those soil organisms, animal groups are soil fauna. They include arthropods, nematodes, molluscs, protozoa, rotifera, enchytraeids, tardigrades and etc. [4]. Both invertebrate and vertebrate soil fauna represent about $23 \%$ of the total diversity of living organisms [5]. Of these, soil invertebrates are the dominant animal group and may have higher biomass on an area basis than above-ground invertebrates or vertebrates [1]. Soil fauna sizes range across four groups of magnitude. The smallest Nematodes and Protozoa (protists) of the microfauna less than $200 \mu \mathrm{m}$ on average live in the water-filled porosity. Microarthropods, Enchytraeidae and the many groups of the mesofauna $(0.2-2 \mathrm{~mm})$ live in the air filled soil porosity. The largest arthropods, Mollusca, Annelida and Crustacea comprise the macrofauna that lives in the surface litter or in nests and burrows that they create in the soil [1, 6-7]. Vertebrates of the megafauna i.e. small rodents, moles, pocket gophers and wild pigs also conspicuous elements of the soil fauna. However, this review focuses specifically on soil invertebrate communities.

Soils fauna are responsible for many ecosystem services in both natural and agricultural system [8]. These functions can be physical effects (regulation of soil structure and soil water regimes), chemical and biological processes (such as degradation of pollutants, decomposition, nutrient cycling, greenhouse gas emission, carbon sequestration, plant 
protection and growth enhancement or suppression) [1]. They help in soil restoration and soil formation through distribution of organic matter and nutrient cycling. Soil fauna likewise represents a good tool to access the soil quality [4]. They are also important players in terrestrial food webs [9-10]. Soil fauna play a dominant role in ecosystem processes, making them particularly significant indicators of soil health. They burrowing and feeding activities result in improved aeration and water infiltration, incorporation of organic matter into the soil, and stabilization of soil aggregates, leading to their designation as 'ecosystem engineers' [6-7]. According to many scholars, the role of soil fauna community requires a vast understanding and an expanding study into proper appreciation of many aspects of soil environment [7, 11-14]

Human activities like mining, farming and exploitation of other biological resources from the soil leads to loss of soil structure and function, reduction in biodiversity, habitat fragmentation, nutrient cycling and organic matter destruction. Soil fauna communities are highly sensitive to environmental variation and destabilization. Which means soil fauna are a useful bio-indicators for human disturbance of ecosystem [15].

Globally, there have been many researches carried out regarding the soil communities [7]. Similarly, there are also some important researches carried out in Africa on biota and biodiversity [16]. Nonetheless, it are still need to be expanded into many aspects of soil and agricultural production, environmental conservation, climate change and land degradation in sub-Saharan Africa; because soil fauna and biodiversity were considered the root of sustainable agriculture in the 21 st century [17]. Therefore, achieving sustainable agriculture in sub-Saharan Africa must focus on food security within its boundaries, and as such, we do believe that there must be an engagement into aspect of soil research relevant to biota and biodiversity in the region [7].

In this review paper first present a general conceptual overview of biotic interactions in soils to explain the intimate links among animals and other soil organisms and their importance for the continued functioning of the soil environment. Then present a synthetic review of the ecosystem services that are affected by soil fauna activities and broadly explain the mechanisms involved. Finally address the practical role of these animal for sustainable management of agriculture, soils and in monitoring soil quality and conservation of ecology. Hence, the objectives of this paper are to provide a concise elucidation of the roles of soil fauna and their biodiversity in the global soil development, soil transformation, ecosystem service, environmental bio indicator and agricultural production. The aims of the review are the following:

(1) To review existing patterns of soil fauna diversity and groups of organisms represented in the ecosystem;

(2) To understand a conceptual framework used in ecology to explore how researchers and farmers perceive, value, and use soil fauna;

(3) To set an agenda to guide future work in extension, management, policy, and research

(4) To provide land users and technical people on the ground with an easy-to-use theses information to the main activities of soil fauna in agriculture and in conservation areas

(5) To provide the knowhow in relation to soil fauna roles as an indicator of ecological impacts and soil health on a site.

(6) To make the forwarding recommendations on the most management techniques for the purpose and propose a methodology for a wider national survey programme to validate soil fauna conservation at a larger spatial resolution.

\section{Soil Fauna Diversity}

Soil biota is a general term refers to all soil organisms living and communicating in soil environment. Ritz, K. et al. [18] considered soil biota as the 'biological engine of the earth', driving and transforming physical, chemical, biological and ecological processes in global soils. Bacteria and fungi are the major group of micro-biota and exist in numerous number in agricultural soil and grassland areas [19-20]. However, most soil animals occur in the surface layer (in the top $30 \mathrm{~cm}$ of soil) because this layer contains the most food ( $\mathrm{C}$ and nutrients) in the form of organic matter and other organisms [1]. Soil animals may move to lower soil layers when conditions at the surface are harsh.

According to body size, soil animals (fauna) classified into micro, meso and macro fauna groups (Table 1.). Microfauna includes small Collembola and mites, nematodes, and protozoa, among others, that generally live in the soil-water film and feed on microflora, plant roots, other microfauna and sometimes larger organisms. Microfauna form the link between the primary decomposers (i.e. microorganisms) and the larger fauna in the detritus food-web in the soil. They are also important to the release of nutrients immobilized by soil microorganisms. The main soil animals in this group are protozoa $[1,7]$.

The mesofauna is the next largest group and the animals range in size from $200 \mathrm{im}$ to $10 \mathrm{~mm}$. in length $(0.1-2 \mathrm{~mm}$ in diameter). These include mainly microarthropod, such as pseudoscorpions, protura, diplura, springtails, mites, small myriapods (Pauropoda and Symphyla) and the worm-like enchytraeids. Mesofauna organisms have limited burrowing ability and generally live within soil pores, feeding on organic materials, microflora, microfauna and other invertebrates [1].

The macrofauna contains the largest soil invertebrates. "It is an invertebrate group found within terrestrial soil samples which has more than $90 \%$ of its specimens (individuals) in such samples visible to the naked eye" [21]. Soil macrofauna groups include organisms like earthworms, millipedes, centipedes, ants, Coleoptera, Isopoda, spiders, slugs, snails, termites, Dermaptera, Lepidoptera larvae and Diptera larvae. In terms of their abundance and their soil forming roles, earthworms, termites and ants are the most important macrofauna components of soils. Indeed, the importance of their activities has caused them to be called "ecosystem engineers" $[6,7]$. 
Table 1. Estimated number of species of soil fauna and organized groups according to body size (Adapted from [7]).

\begin{tabular}{lllll}
\hline Size & Group & Known species & Estimation total species & \% known \\
\hline \multirow{3}{*}{$<200 \mu \mathrm{m}$} & Microfauna & 1500 & 200000 & $7.5 \%$ \\
& Protozoa & 5000 & 400000 & $1.3 \%$ \\
\multirow{3}{*}{$0.2-2 \mathrm{~mm}$} & Nematodes & & & \\
& Mesofauna & $0.000-30.000$ & 900.000 & $2.2-3.3$ \\
& Mites & 6.500 & 24.000 & 27.1 \\
& Collembola & & & \\
& Macrofauna & 8.800 & 15.000 & 58.7 \\
& Ants & 1.600 & 3.000 & 53.3 \\
& Termites & 3.600 & No estimate & No estimate \\
\hline
\end{tabular}

Macrofauna burrow and are important in mixing the soil known as bioturbation. Macroarthropods and Mollusca are constant inhabitants of litter and, to a lesser extent, of soils, but they have generally more specific ecological roles. Thus, most live in the litter or in the upper few centimetres of soil; saprophagous arthropods play a major role in the breakdown of surface litter $[1,7]$.

Soil macro and meso fauna are groups of biota that are also very important in soil medium [22]. They play a vital role in moving soil particles, transforming soil structure and enhancing soil moisture [18]. Earthworms are considered numerous and grouped into 23 families, 700 genera and many species [14]. Termites are described as grass harvester, surface litter feeders, wood feeders and soil feeders 'humivores' [23]; probably up to 10,000 species exist in soil medium [22]. Arthropods are grouped into Coleoptera which believe to cover $48 \%$ of the population followed by Acari and Formicidae species [23]. Nematodes are considered the major consumers classified as bacteria feeders, fungal feeders, plant feeders, predators and omnivores [14]. Generally, the sustainable function of natural and agricultural soil ecosystems is dependent on the contribution that these groups of biota and their biodiversity offer [24].

\section{Roles of Soil Fauna in Ecosystem Goods and Services}

The functions of soil fauna depend largely on the efficiency of their digestive systems and on the occurrence and abundance of the biological structures that they produce in the soil. Using these two criteria, three large functional groups of invertebrates can be distinguished: micropredators, litter transformers, and ecosystem engineers. The micropredator group contains the smallest invertebrates, protozoa and nematodes. They do not produce organo-mineral structures, and their principal effect is to stimulate the mineralization of soil organic matter (SOM) [1]. In the litter-transformer group, mesofauna and some macrofauna organisms are involved in litter decomposition. When these invertebrates re-ingest their excretions, which serve as incubators for bacteria, they assimilate metabolites liberated by microbial actions [1].

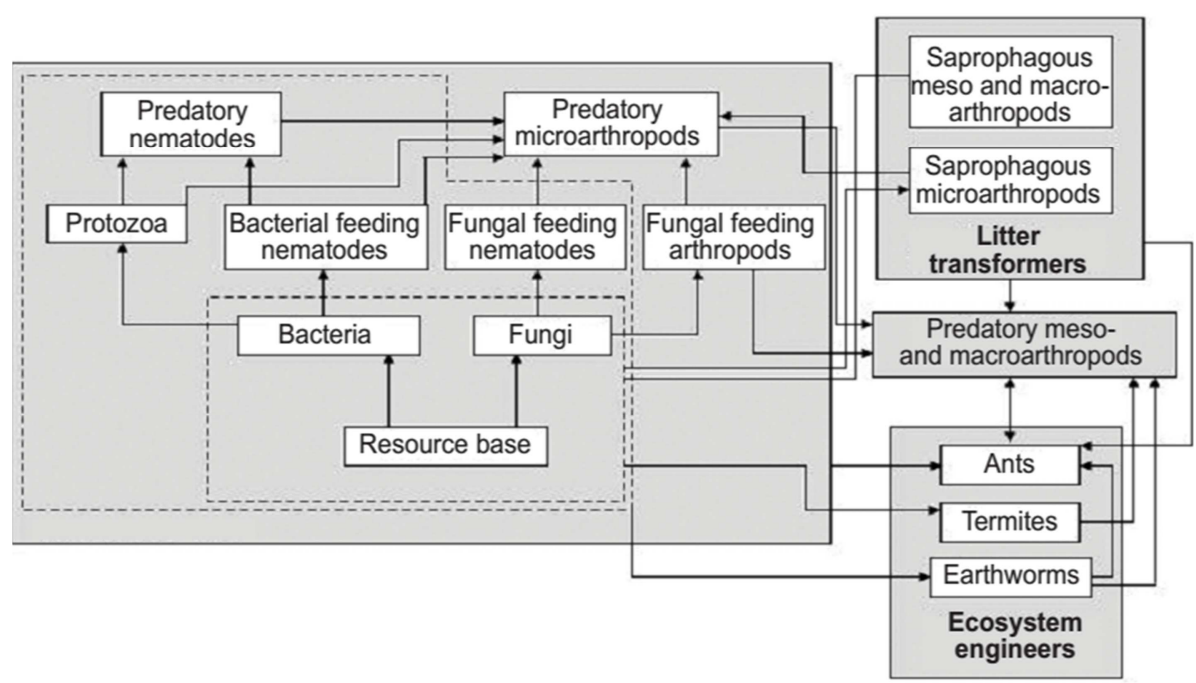

Figure 1. Diagram of a soil food-web Source: Adapted from [1].

The "ecological engineers" or "ecosystem engineers" are those organisms that produce physical structures through which they can modify the availability or accessibility of a resource for other organisms [1]. Among the innumerable life forms that inhabit soils, only a small number of macro invertebrates (earthworms, termites and ants) are distinguished by their capacity to excavate soil and produce a wide variety of organo-mineral structures, such as excretions, nests, mounds, macropores, galleries and caverns. Their structures have been described as "biogenic structures" [25]. 
Their activities and biogenic structures can modify the abundance or structure of their communities [1]. The functional role of these structures is thought to be important because they represent sites where certain pedological processes occur: stimulation of microbial activity; formation of soil structure; SOM dynamics; and exchange of water and gases [1].

Soil organisms (soil microbe and fauna) are the main mediators of soil functioning. These functions can be pictured as having a hierarchical relationship. Figure 1 illustrates the hierarchical organization of the determinants of soil processes: climate, soil characteristics - especially the abundance and types of clays and nutrients - and the quality of the organic materials input. The series of factors affecting soil functioning are determined by both spatial and temporal scales [1].

Invertebrates participate in the regulation of ecosystem processes and the delivery of ecosystem services at the usually large scale at which they are perceived, from parcels allocated to one type of land use to landscapes or watersheds $[1,26]$. They contribute significantly to the production and delivery of soil ecosystem services in many ways (Table 2). Moreover they serve as Water supply, Nutrient cycling, Soil formation, primary production, Flood erosion control, climate regulation..etc..

1) Water supply: Invertebrates tend to decrease surface runoff by their effects on surface roughness, and water infiltration and they create structural porosity in soils. The diversity of pore shapes and sizes may allow soils to store water at a wide range of potentials [27, 28].

2) Nutrient cycling: Their contributions to nutrient cycling have been extensively studied and modeled: their principal contribution seems to result from the comminution of litter and the selective activation of microbial activities [28]. In addition to their instantaneous enhancement of mineralization and humification of organic substrates, they create biogenic structures that may act as incubators of microbial activities or microsites for carbon and nutrient sequestration. This ability to affect nutrient cycling at several scales of time and space is an important attribute of soil invertebrates as regulators of nutrient cycling. Much is known of invertebrate effects on $\mathrm{C}$ and $\mathrm{N}$ cycling, much less on $\mathrm{P}$ and virtually none on that of $\mathrm{K}$, $\mathrm{Ca}$ and other important macro and micro nutrients [28]. Invertebrates are generally considered key actors in the buffering systems that allow efficient local recycling of nutrients and prevent leakage from impaired ecosystems towards low-lying aquifers, streams and oceans. This effect however has never been quantified in any ecosystem or large landscape unit [28].

3) Primary production: Primary production is greatly affected by soil invertebrate activities, directly and indirectly. According to Lavelle et al. [26], enhanced primary production has been generally attributed to five main processes: 1 . Enhanced nutrient release in plant rhizosphere; 2. Stimulation of mutualistic micro-organisms, mycorrhizae and N-fixingmicro organisms; 3. Enhancement of plant vigor and protection against pests and diseases, above and below ground; 4. Positive effects on soil physical structure and 5. Production of plant-growth promoters by microorganisms.

4) Soil formation: Soil formation is another long term process for which soil invertebrate activities have not been much considered. In spite of the acknowledged role of earthworms in the creation of "vermisols" and the belief expressed by a few authors that micro aggregates observed in oxisols have been formed by termites, the consequences of 1000 or more years of faunal activities accumulated over time and spatial scales 4-6 orders of magnitude lower is mostly ignored. There are a few known examples, however, where drastic changes in soil macrofauna communities occur following forest clearing, or the explosion of populations of invasive species, have significantly changed the soil profile in surprisingly short periods of time. An average annual deposition of 10 Tonnes of fine soil per ha at the soil surface by ants, termites, earthworms and other ecosystem engineers results in an approximate $1 \mathrm{~mm}$ downward movement of gravels and stones [29].

5) Climate regulation: Climate regulation is clearly influenced by soil invertebrate activities, through the accumulation over large periods of time of small-scale effects. Soil aggregation and enhanced humification are the main mechanisms involved in this process. Sequestration of $\mathrm{C}$ in compact and stable aggregates is regarded as an important process whereby soils accumulate $\mathrm{C}$ thus preventing its rapid release in the form of greenhouse gases. Enhanced humification also tends to transform large amounts of relatively labile $\mathrm{C}$ into forms that are much more resistant to further decomposition and hence to slower greenhouse gas release from soils.

Table 2. Summarizes of the Contributions of soil fauna to the provision of ecosystem goods and services (Adapted from [26]).

\begin{tabular}{|c|c|c|c|c|}
\hline Service types & Goods/ services & Ecosystem process & Soil invertebrate contribution & Indicator of faunal contribution \\
\hline Production & Water supply & $\begin{array}{l}\text { Infiltration and storage of } \\
\text { water in soil pore systems }\end{array}$ & $\begin{array}{l}\text { Building and maintenance of stable porosity through } \\
\text { bioturbation and burrowing }\end{array}$ & $\begin{array}{l}\text { Proportion and arrangement of } \\
\text { biogenic structures in soil } \\
\text { Water-holding capacity }\end{array}$ \\
\hline \multirow[t]{2}{*}{ Support } & Nutrient cycling & $\begin{array}{l}\text { Decomposition } \\
\text { Humification } \\
\text { Regulation of nutrient losses } \\
\text { (leaching denitrification) }\end{array}$ & $\begin{array}{l}\text { Comminution, selection/ activation of microbial } \\
\text { activities }\end{array}$ & $\begin{array}{l}\text { Litterbag decomposition } \\
\text { assessments } \\
\text { Profile of soil organic matter } \\
\text { Measure of Organic matter content } \\
\text { in the different soil fractions }\end{array}$ \\
\hline & Soil formation & Pedogenesis & Bioturbation, Surface deposition, Particle selection & $\begin{array}{l}\text { DNA and NIRS analyses in } \\
\text { biogenic structures }\end{array}$ \\
\hline
\end{tabular}




\begin{tabular}{|c|c|c|c|c|}
\hline Service types & Goods/ services & Ecosystem process & Soil invertebrate contribution & Indicator of faunal contribution \\
\hline \multirow[b]{3}{*}{ Regulation } & & $\begin{array}{l}\text { Stimulation of symbiotic } \\
\text { activity in soil }\end{array}$ & $\begin{array}{l}\text { Selective microbial enhancement in functional } \\
\text { domains }\end{array}$ & Soil and humus morphology \\
\hline & $\begin{array}{l}\text { Primary } \\
\text { production }\end{array}$ & $\begin{array}{l}\text { Indirect production in the } \\
\text { soil of molecules recognized } \\
\text { by plants as hormones } \\
\text { Protection against pests and } \\
\text { diseases communities }\end{array}$ & $\begin{array}{l}\text { Control of pests through biological interactions; } \\
\text { enhanced capacity of plant response }\end{array}$ & $\begin{array}{l}\text { Soil DNA assessments } \\
\text { Soil faunal communities } \\
\text { Indices of plant vigor }\end{array}$ \\
\hline & $\begin{array}{l}\text { Climate } \\
\text { regulation }\end{array}$ & $\begin{array}{l}\text { Production/consumption of } \\
\text { greenhouse gases } \\
\text { Organic matter storage in } \\
\text { soil and biomass }\end{array}$ & $\begin{array}{l}\text { Organic matter sequestration instable biogenic } \\
\text { macro- aggregates } \\
\text { Enhanced formation of resistant humic compounds }\end{array}$ & Stable biogenic macro-aggregates \\
\hline
\end{tabular}

The importance of the functions performed in soils by macrofauna and the physical, chemical and biological changes induced in a soil environment as a consequence of its activity make it a vital part of all ecosystems, including agro-ecosystems. According to FAO [1], the beneficial effects of soil fauna on agricultural productivity that may be affected include:

(1) mixing organic matter through the soil.

(2) organic matter decomposition, mineralizing nutrients and soil aggregation;

(3) improving and maintaining soil structure;

(4) breakdown of toxic compounds, both metabolic by-products of organisms and agrochemicals;

(5) inorganic transformations that make available nitrates, sulphates and phosphates as well as essential elements such as iron ( $\mathrm{Fe})$ and manganese $(\mathrm{Mn})$;

(6) controlling pathogen populations;

\section{Ecosystem Engineers of Soil Fauna}

Soil invertebrates are key mediators of soil function for the diversity of ecosystem engineering processes in which they partake. The comminution and incorporation of litter into soil, the building and maintenance of structural porosity and aggregation in soils through burrowing, casting and nesting activities, the control of microbial communities and activities, plant protection against some pests and diseases, acceleration of plant successions are among the many effects they have on other organisms through their activities [26, 30-31].

Of major importance in ecosystem and soil development and maintenance are the so-called "ecosystem engineers" - as these species control, either directly or indirectly, the availability of resources to other species [6]. These organisms physically modify, maintain and create new habitats for other organisms. One effect of such organisms is to create higher habitat diversity, which may in turn increase species diversity [29]. An example of physical ecological engineers is plant roots that create large voids (spaces) in the soil through root decay [6]. Other ecosystem engineers are the termites and earthworms that play a major role in moving, mixing and aerating the soil through their burrowing. Other organisms including higher plants and animals also play substantial roles in this respect [1].
Ecosystem engineers of any kind have the potential to enhance ecosystem function in soil, probably more than in any other ecological medium. This is due to the unique constraints faced by life in the subterranean environment. Compaction tends to severely limit movement, aeration and water storage unless porosity is created by powerful physical or biological processes [26]. According to FAO [1], the effects of soil fauna on soil can be divided into three classes: physical, chemical and biological effects. These effects are determined by the functional group involved in the process.

\subsection{Physical Engineering}

The ability of organisms to alter the environments of other organism through their mechanical activities is physical engineering. It is any physical transformation in the environment that modifies the resources for other organisms [26]. In soils, this effect of invertebrates is now largely acknowledged and many examples have been proposed across all scales [32]. Soils host a number of such organisms among which earthworms, termites and ants are the most commonly cited examples [31]. One feature common to all these organisms is the disproportionate magnitude of their effects in terms of their biomasses and the way that their activity modulates soil resource accessibility for other soil organisms. Examples also include the modification of microbial and soil invertebrate communities by earthworm activities or the impact of ants or earthworms on soil seed banks and seedling recruitment [26, 30, 33]. Significant effects of such small invertebrates as Enchytraeidae on physical properties have been frequently observed in soils. Invertebrates of the soil mesofauna are well known for their physical effects on humic material [26].

Ants, termites and earthworms have been widely described and documented major groups of soil ecosystem engineers [26]. The distribution of communities among different functional groups (for example 'compacting' vs. "decompacting") therefore becomes critical to soil functioning. In Amazonian oxisols near Manaus (Brazil), diverse communities of soil engineers in natural forests produce a large diversity of biogenic structures (voids, pores, fabrics and aggregates of all sizes) which provide these soils with highly favorable hydraulic properties. When deforested, these soils tend to lose the greater part of this diversity and 
invasive species may even severely impair their physical function by producing excessive amounts of a single type of structure [26, 34].

In sloping environments in West Africa [26], earthworms have been report to trigger soil creep through the continuous erosion of surface casts and down-slope transport of their materials. [26] describe rather sophisticated contributions of Isopods to the regulation of physical (soil erosion) and chemical (soil desalinization) soil processes at the scale of watersheds in the southern Negev Desert Highlands, Israel. The roles of termites and ants in shaping geomorphology and soil profiles at landscape levels have been well documented [26]. Moreover, there are five main physical effects of soil fauna:

1) Macromixing: Move an important quantity of soil, bringing back to the surface mineral matters from deeper horizons and burying the organic matter from the surface horizons, from litter and from excrements by soil fauna e.g. ants, termites, earthworms and ground beetles

2) Micromixing: Other groups of soil macrofauna influence soil structure in a less spectacular way, but the micromixing that they realize is as important as macromixing. These organisms, mainly represented by Diptera larvae, have a more limited capacity to dig the soil. They stay on the soil surface where they realize a fundamental task for the incorporation of organic matter to soil. However, they can be carried into soil by leaching to a depth of up to $60 \mathrm{~cm}$.

3) Gallery construction: Gallery (burrow) formation is very important for soil aeration and water flux. For example, earthworms and termites develop networks of galleries that improve large spaces in the soil macro-porosity by $20-100$ percent [1].

4) Litter fragmentation: one of the most important activities of soil fauna is fragmentation of dead wood (lignin material), carcass and litter. It has a major effect on organic matter evolution in soil, conditioning the activity of bacteria, fungi and microfauna populations. Fragmentation is performed by animals feeding on decayed plant material and dead animals called (phytosaprophagous).

5) Aggregate formation: After litter has been fragmented, it is easier for organic matter to be broken down into the stable form known as "humus", and then to form soil aggregates the clumping together of soil particles forming a crumbly healthy structure. Earthworms, termites, millipedes, centipedes and woodlice ingest soil particles with their food and contribute to aggregate formation by mixing organic and mineral matter in their gut.

\subsection{Chemical Engineering}

Some organisms may trigger effects that are disproportionate to their size and activity by producing chemical substances with hormone-like or other physiological effects. An example of this effect is the release of organic acids in faecal pellets of invertebrates that live in temperate forest litters. Soil invertebrates produce two kinds of feces within which contrasting reactions occur. The casts of anecic earthworms (those that ingest a mixture of soil and surface litter and inhabit galleries) are macro-aggregates of 2.5-10 $\mathrm{mm}$ in diameter and form 'macro aggregate closed systems' in which intense microbial activity favors a rapid flocculation of soluble organic compounds that have no effect on mineral weathering. Arthropods that live in the surface litter and holorganic horizons produce small $(<100 \mu \mathrm{m})$ and unstable faecal pellets. Microbial activity is generally low and these aggregates are subject to intense leaching. The aggressive organic compounds released promote intense weathering and the loss of clay minerals [26].

Production of hormone-like and energy-rich substances such as root exudates, earthworm and termite mucus and saliva has been indicated in a number of publications [35]. Research on this topic is still in its infancy and the general hypothesis is that the effects observed are often due to an intermediate effect on microorganisms that, when activated, further release plant-growth-promoting, allelopathic and other substances. Intestinal mucus plays a significant role in the selection and stimulation of microbial activities in the earthworm guts [26] and the effects of earthworm cutaneous mucus on microbial selection have also been demonstrated [28]. Termite saliva has comparable effects and large numbers of similar cases [26].

The most important chemical effect of macrofauna on soil is the modification of food quality through its passage in the gut and particularly the mineralization of organic matter and the release of nutrients. Soil macrofauna also influences soil chemical composition through the deposition of excrement. Chemical effect of macrofauna on soil is direct and indirect [1].

The main indirect chemical effect is the mineralization of $\mathrm{N}$, $\mathrm{P}$ and $\mathrm{S}$ through the activation of microflora. Soil microorganisms represent an important proportion of the soil living component (60-80 percent). However, in order to be active, they need to be in contact with SOM (which they feed on). Because of their inability to move in soil to search for food, microorganisms are only active during short periods of time (the time necessary to consume the organic matter around them) and in a limited number of microsites (where temperature and moisture conditions are suitable for their activity). The rest of the time, soil microorganisms are "in dormancy" and they are able to survive "hard times" in this way [1]. The contrast between the potential of soil microorganisms for an extremely fast turnover of organic matter and the field reality has been called the "Sleeping Beauty Paradox" Macrofauna that has the ability to move the soil and change environmental conditions at the scale of microorganisms can interrupt this dormancy (acting as "Prince Charming"), providing assimilable substrates (root exudates, earthworm mucus and other materials) that initiate the metabolic capabilities of microorganisms. Hence, they appear to be major regulators of microbial activities [1]. 


\subsection{Biological Engineering}

Interactions of below ground communities with plants and other above-ground communities often result in significant modifications to successional dynamics. This may sometimes be a consequence of a general effect of invertebrates on nutrient cycling: the intense activity of earthworms in the senescent and early phases of natural succession in alpine spruce forests boosts the growth of tree seedlings and prevents the forest from being replaced by Myrtilus shrub communities [26].

In a natural soil, a complex and dynamic balance exists between the different groups of organisms with different feeding habits. Predation and competition are the main factors controlling this equilibrium. Predation has an important role because it establishes a balance between the number of individuals and the quantity of available resources. Competition is another way to maintain soil fauna populations in balance with soil resources [1].

Another biological effect of soil macrofauna is the disappearance of dead animal material. This work is realized by necrophagous (which feed on dead and/or decaying animals) and coprophagous organisms (feeding on dung or excrement) such as Diptera larvae, Coleoptera and Lepidoptera larvae and adults. They clean the soil surface and incorporate organic matter into soil. In addition, soil macrofauna disseminates bacteria and spores through excrement dispersion in soils or by on-body transport. Earthworms determine the vertical repartition depth in soil [1]. .

De Deyn et al. [41] also showed how plant parasitic Nematodes may accelerate plant successions by successively weakening plant populations that have arrived at a transitient dominance situation, and facilitate their replacement by plant of another species still not attacked by parasites. The effects of earthworms and ants on selective seed dispersal and growth stimulation are other still little explored processes whereby biological engineering mediated by soil invertebrates may ultimately affect the provision of ecosystem goods and services. Earthworms for example may ingest large amounts of viable seeds, which are later deposited in their casts within the soil profile or at its surface $[26,30]$. In so doing, they generate vertical seed movements and may alter the composition of the soil seed bank [26]. Surface casts may also constitute a regeneration niche [26] for some plant species, as their seeds may have a greater chance to germinate than those of the soil seed bank [26, 30].

Thus, through their different activities and effects on soil, soil organisms create and accumulate structures that give soils specific architectures [36]. Networks of galleries, the accumulation and spatial array of biogenic aggregates and surface deposits are among the conspicuous features that can be observed in the field. The nature and array of these structures depend on the organisms that have produced them. The physical and chemical parameters of the soil that was used to make the biostructures are also important as they determine the resistance and persistence of these structures [1].

\section{Soil Fauna as Indicators of Soil Function and Quality}

Interactions between microorganisms and macrofauna are the basis of the biological systems of regulation that determine soil function [29]. A soil ecosystem would be vulnerable to environmental changes, disturbances and other stresses without high biological diversity [37]. Biological characteristics of soil play a vital role in defining soil quality and health. Soil quality is an effective indicator of soil fertility and reflects changes in soil properties [38]. Healthy soil is footing of a healthy and productive cropping system. Soil health is the capacity of a soil to function within ecosystem boundaries to sustain biological productivity, maintain environmental quality, and promote plant and animal health [39]. It has been synthesized the following characteristics: 1) high biological diversity, 2) high community stability that can provide resilience and self-recovery to chemical and biological disturbance, 3) ability to maintain the integrity of nutrient cycling and energy flow, 4) suppression of multiple pests and pathogens, 5) ability to improve plant health, and 6) maintenance of water and air quality [37].

Soil invertebrates are clearly important components of soil function and any change occurring in soil properties is likely to affect them. Their effects in different land use types have been widely studied [28]. Consequently, they may be considered highly responsive indicators of many aspects of soil quality [40]. Comprehensive indicators based on the composition and abundance of their communities are currently being developed [28]. Soil invertebrates also fill important niches in the environment because they influence nutrient flow, improve soil aeration and fertility, and alter plant community structure. Relatively short generation time allows invertebrates to respond rapidly to changes in environmental quality, whereas relatively poor ability to disperse generally prolongs the recolonization process [1]. These characteristics predispose soil invertebrates for use as indicators of ecological disturbance.

Soil fauna have advantages as bioindicators due to two reasons. First, they are one or two steps higher in the food chain, and they can serve as integrators of physical, chemical, and biological properties related with their food resources. Second, their generation time (days to years) is longer than metabolically active microbes (hours to days), making them more stable temporally [39].

Soil faunas are highly sensitive to environmental disturbance. For instance, they quickly respond to soil management practices and are affected by landscape characteristics. These characteristics made soil invertebrates a valuable tool for monitoring landscape quality and the effects of change over time and space, and thus can be valuable as bio-indicators. The importance of terrestrial invertebrates in the assessment of environmental characteristics and changes in agro ecosystems has been widely demonstrated across organic, integrated and conventional farming techniques. The anthropic impact and alteration of natural landscape have also been usefully assessed by these bio-indicators. Nematodes are excellent bio-indicators for environmental change, soil status 
and health as once they are present in a habitat and in proximity of hosts conducive to their development, they may rapidly multiply [39].

\section{Cause and Management of Soil Fauna Reduction}

\subsection{Cause of Soil Fauna Reduction}

The loss of biodiversity is a dramatic manifestation of the poor management of natural resources. The biological impoverishment caused by inappropriate management could affect the continuous dynamic functioning of ecosystems. In this regard, the removal of any species may increase the susceptibility of the system to the perturbation which may be due to a natural event, such as climatic variability, or human induced, for example toxicity of an agrochemical or effects of severe compaction due to repetitive tillage [1].

The use of heavy machinery to prepare soil for agriculture has caused soil compaction. This type of soil management has led to important changes in soil fauna abundance and diversity. After several years of culture, fields are left fallow. During this period, the soils are recolonized by soil fauna. However, the soil compaction makes this process difficult and the composition of the soil macrofauna is dominated few species. These species usually build their nests in soil, but soil compaction modifies their behaviour. This action completely prevents the possibility of further agricultural uses of the land and cause of other soil fauna lose [1].

Transformation of forest zones into pastures leads to the degradation of the soil as a consequence of mismanagement, phytosanitary problems, poor soil fertility and soil structural modification (linked to fauna activity). Where the forest is converted to pasture, first the machines and then the cattle trampling the soil lead to severe soil compaction, particularly in the top 5-10 cm. However, the most important consequence is that the native soil macrofauna communities are altered radically, with most of the native taxa disappearing. These are replaced by an opportunistic invading species [1].

The reduction of aboveground biodiversity is normally associated with the alteration of several environmental parameters including the carbon supply to the soil, which provides the basis for a more or less diversified soil population [34]. The reduction in diversity of soil organisms causes a dysfunctioning of the ecosystem. This dysfunctioning may result in disequilibrium between beneficial and harmful organisms, which can lead to harmful organisms to become dominant because of the lack of predators [1]). In other cases, as result of a reduction in macrofauna, the activities of a beneficial organism can increase immoderately and become detrimental and a serious problem. Barros et al. [34] showed the results of dysfunctioning caused by the disequilibrium between compacting and uncompacting macro- invertebrates.

\subsection{Management Practices on Soil Fauna}

Improvements in soil management to avoid a reduction in soil macrofauna diversity and to guarantee suitable soil conditions for these organisms to develop are the only way to ensure long-term soil functioning and to protect cultures from pests. Thus, land management has a dramatic effect on soil fauna communities. Primary forests have rather diverse and abundant fauna with density and biomass two to three times higher than that in managed systems. Epigeic and litter fauna is well represented and the biological activity is mainly concentrated in the top $20 \mathrm{~cm}$ of soil. Land-use management has an important impact on soil and its functional role in maintaining ecosystem processes. It generally results in dramatic and rapid changes in vegetation that are likely to affect soil invertebrate communities significantly [1]. However, soil fauna can be managed by indirect and direct practices.

Indirect management practices are used interventions are a means of managing soil biotic processes by manipulating the factors that control biotic activity (habitat structure, microclimate, nutrients and energy resources) rather than the organisms themselves. Examples of indirect interventions include most agricultural practices, such as application of organic materials to soil, tillage, fertilization, irrigation, green manuring and liming as well as cropping system design and management [18]. Pest management can also benefit from conservation practices that enhance biological activity and diversity, and hence competitors and predators as well as alternative sources of food. For example, most nematode species can be reduced significantly by the application of organic matter, which stimulates the action of several species of fungi that attack nematodes and their eggs [1].

Direct management practices involve intervening in the production system in an attempt to alter the abundance or activity of specific groups of organisms. Examples of direct interventions include: (i) inoculation of seeds or roots with rhizobia, mycorrhizae, fungi and rhizobacteria for enhanced soil fertility; and (ii) inoculation of soil or the environment with biocontrol agents (pest or disease), antagonists and beneficial fauna [1].

\section{Conclusions and Further Recommendations}

It is important to preserve soil fauna diversity in order to maintain the integrity of the processes that sustain the ecosystem services, such as primary and agricultural productivity, nutrient cycling and formation of soil. Soil fauna are also important to maintaining resilience, i.e. the soil capacity to recuperate its initial situation after a natural or human-induced perturbation. Thus, a system that is functioning properly is one that will persist despite natural environmental fluctuations.

Clearing forests or grasslands for cultivation modifies the soil environment drastically and, hence, also modifies the numbers and kinds of soil fauna. The quantity and quality of plant residues and the number of plant species are, in general, greatly reduced, as a result the range of habitats and foods for 
soil organisms is reduced significantly. The use of large quantities of agrochemicals (pesticides, herbicides and inorganic fertilizers) and tillage practices has a negative influence on soil fauna communities by reducing their numbers and hence the beneficial ecological functions in which they participate.

Researchers investigating local soil knowledge and management should give consideration to the biological component of soil. In particular, researchers should direct attention not just to observations of soil fauna, but also to how these organisms are considered in agricultural activities and to the belief systems that influence agricultural practices and perceptions of soil life. We encourage collaborative partnerships among social scientists, soil scientists, farmers, and extension workers to jointly investigate these issues.

\section{References}

[1] FAO (2008). Soil macrofauna Field manual Technical level. Rome, 2008.

[2] Decaëns, T. (2010). Macroecological patterns in soil communities. Global Ecology and Biogeography 19: 287-302.

[3] Pauli, N., L. K. Abbott, S. Negrete-Yankelevich, and P. Andrés. (2016). Farmers' knowledge and use of soil fauna in agriculture: a worldwide review. Ecology and Society 21(3): 19.

[4] Menta, C., Conti, F. D., Pinto, S., Leoni, A., Lozano-Fondón, C. (2013). Monitoring soil restoration in an open-pit mine in northern Italy. Applied Soil Zoology, 83: 22-29.

[5] Decaëns, T. Jiménez, J. J. Gioia, C. Measey, G. J. Lavelle, P. (2006). The values of soil animals for conservation biology, Eur. J. Soil Biol. 42 S3-S15.

[6] Jones, C. G., Lawton, J. H. \& Shachack, M. (1997). Positive and negative effects of organisms as physical ecosystem engineers. Ecology, 78(7): 1946-1957.

[7] Usman, S., Muhammad, Y. Maigana, A. C. (2016). Roles of soil biota and biodiversity in soil environment - A concise communication. Eurasian J Soil Sci., 5 (4) 255 - 265.

[8] Bardgett, R. D., and W. H. van der Putten. (2014). Belowground biodiversity and ecosystem functioning. Nature 515: 505-511.

[9] Bilde, T., Axelsen, J. A., Toft, S. (2000). The value of Collembola from agricultural soils as food for a generalist predator. Journal of Applied Ecology 37, 672-683.

[10] McNabb, D. M., Halaj, J., Wise, D. H., (2001). Inferring trophic positionsof generalist predators and their linkage to the detrital food web in agro ecosystems: a stable isotope analysis. Pedobiologia 45, 289-297.

[11] Kramer, C., Gleixner, G., (2008). Soil organic matter in soil depth profiles: Distinct carbon preferences of microbial groups during carbon transformation. Soil Biology and Biochemistry 40(2): 425-433.

[12] Jenney, H., (2009). Factors of soil formation: A system of quantitative pedology. Dover Publications, New York, USA. 320 p.
[13] Culman, S. W., Young-Mathews, A., Hollander, A. D., Ferris, H., Sánchez-Moreno, S., O'Geen, A. T., Jackson, L. E., (2010). Biodiversity is associated with indicators of soil ecosystem functions over a landscape gradient of agricultural intensification. Landscape Ecology 25(9): 1333-1348.

[14] Usman, S., (2013). Understanding soils: Environment and properties under agricultural conditions. Publish America, Baltimore, USA. 151p.

[15] Zhang, L., Zhang, X., Cui, W. (2014). Relationship between land use pattern and the structure and diversitiy of soil meso-micro arthropod community. Springer Science+Business Media (Ecotoxicology), 23: 707-717.

[16] Jürgens, N., Schmiedel, U., Haarmeyer, D. H., Dengler, D., Finckh, M., Goetze, D., Gröngröft, A., Hahn, K., Koulibaly, A., Luther-Mosebach, J., Muche, G., Oldeland, J., Petersen, A., Porembski, S., Rutherford, M. C., Schmidt, M., Sinsin, B., Strohbach, B. J., Thiombiano, A., Wittig, R., Zizka, G., (2012). The BIOTA Biodiversity Observatories in Africa-a staandardized framework for large-scale environmental monitoring. Environmental Monitoring and Assessment 184(2): 655-678.

[17] FAO, (2007). Soil Biota and Biodiversity: the "Root" of Sustainable Agriculture. Food and Agricultural Organization of United Nation, Rome, Italy. pp. 1-4.

[18] Ritz, K., McHugh, M., Harris, J. A., (2004). Biological diversity and function in soils: contemporary perspectives and implications in relation to the formulation of effective indicators. In: Agricultural soil erosion and soil biodiversity: Developing indicators for policy analyses. Francaviglia, R. (Ed.), OECD, Paris, France. pp. 563-572.

[19] Riesenfeld, C. S., Schloss, P. D., Handelsman, J., (2004). Metagenomics: genomic analysis of microbial communities. Annual Review of Genetics 38: 525-552.

[20] De Vries, F. T., Hoffland, E., van Eekeren, N., Brussaard, L., Bloem, J., (2006). Fungal/bacterial ratios in grasslands with contrasting nitrogen management. Soil Biology and Biochemistry 38(8): 2092-2103.

[21] IBOY.2000. Soil macrofauna: an endangered resource in a changing world. Report of an international workshop held at IRD, Bondy (France) 19-23 June 2000. Downloadable at URL: http://www.bondy.ird.fr/lest/iboy/workshop-report.pdf.

[22] Coleman, D. C., (2001). Soil biota, soil systems, and processes. In: Encyclopaedia of Biodiversity. Levin, S. A. (Ed). Vol. 5, Academic Press. pp. 305-214.

[23] FAO, (2005). The importance of soil organic matter: key to drought-resistant soil and sustained food production. FAO Soils Bulletin, No. 80. Food and Agricultural Organization of United Nation, Rome, Italy. pp. 11-47.

[24] Barrios, E. (2007). Soil biota, ecosystem services and land productivity. Ecological Economics 64: 269-285.

[25] Anderson, J. M. (1995). Soil organisms as engineers: microsite modulation of macroscale processes. In: Jones, C. G. \& Lawton, J. H. (eds.) Linking Species and Ecosystems. Chapman and Hall, London. pp. 94-106.

[26] Lavelle, P., Decaëns, T., Aubert, M., Barot, S., Blouin, M., Bureau, F., Margerie, P., Mora, P., Rossi, J.-P. (2006). Soil invertebrates and ecosystem services. European Journal of Soil Biology 42 (2006) S3-S15. 
[27] Le Bayon, R. C. Binet, F. (1999). Rainfall effects on erosion of earthworm casts and phosphorus transfers by water runoff, Biol. Fert. Soil 30 : 7-13.

[28] Lavelle P., Rouland C., Binet F., Diouf M., Kersanté A. (2005). Regulation of microbial activities by roots and soil invertebrates, in: F. Buscot, A. Varma (Eds.), Microorganisms in soils: roles in genesis and functions. Soil Biology series, vol. 3, Springer Verlag, Berlin, 2005, pp. 291-305.

[29] Lavelle, P. \& Spain, A. (2001). Soil Ecology. Kluwer Academics, The Netherlands.

[30] Decaëns T., Mariani L., Betancourt N., Jiménez J. J. (2003). Seed dispersion by surface casting activities of earthworms in Colombian grasslands, Acta Oecol. 24 (2003) 175-185.

[31] Jouquet P., Dauber J., Lagerlof, Lavelle J. P., Lepage M. (2006). Soil invertebrates as ecosystem engineers: intended and accidental effects on soil and feedback loops, Appl. Soil Ecol. 32 (2006)153-164.

[32] Plante A. F., McGill W. B. (2002). Soil aggregate dynamics and the retention of organic matter in laboratory-incubated soil with differing simulated tillage frequencies, Soil Till. Res. 66 (1) (2002) 79-92.

[33] Milcu A., Schumacher J., Scheu S. (2006). Earthworms (Lumbricus terrestris) affect plant seedling recruitment and microhabitat heterogeneity, Funct. Ecol. 20 (2006) 261-268.
[34] Barros E., Curmi P., Hallaire V., Chauvel A., Lavelle P. (2001). The role of macrofaune in the transformation and reversibility of soil structure of an oxisol in the process of forest to pasture conversion, Geoderma 100 (2001) 1193-1213.

[35] Lavelle P. and Spain A. V. (2006). Soil ecology. 2nd ed, Kluwer Scientific Publications, Amsterdam, 2006.

[36] Lavelle, P. (2002). Functional domains in soils. Ecol. Res., 17(4): 441-450.

[37] Wang, K.-H. and Hooks, C. R. (2011). Managing Soil Health and Soil Health Bioindicators through the Use of Cover Crops and other Sustainable Practices.

[38] Glover, J. D., Reganold, J. P., Andrews, P. K., (2000). Systematic method for rating soil quality of conventional, organic, and integrated apple orchards in Washington state. Agric. Ecosyst. Environ. 80, 29-45.

[39] Mekonen, S., Petros, P. and Hailemariam, M. (2017). The Role of Nematodes in the Processes of Soil Ecology and Their Use as Bioindicators. Agric. Biol. J. N. Am., 8(4): 132-140.

[40] Paoletti, M. G. (1999). Invertebrate biodiversity as bioindicators of sustainable landscapes, Elsevier, Amsterdam.

[41] De Deyn G. B., Raaijmakers C. E.,. Zoomer H. R, Berg M. P., de Ruiter P. C., Verhoef H. A. (2003). Soil invertebrate fauna enhances grassland succession and diversity, Nature 422 (2003) 711-713. 